\title{
Principios cristianos en los cuentos de Rubén Darío
}

Gi Rubén Darío ha llegado a ser universalmente tenido por un mundano Ny epicúreo, que vivió una vida desprovista de valores, fuera de aquellos dictados por su arte, se debe, sin duda, a que la tendencia general de sus biógrafos y críticos ha sido la de hacer resaltar los aspectos mundanos de su obra. Pero el observador atento de sus escritos descubre en ellos mucho que encierra un significado harto más profundo que lo que podría ser clasificado superficialmente como simplemente mundano o puramente estético.

Este es, pues, el objeto del presente estudio: ahondar dentro de estos elementos, poco estudiados hasta ahora, y tratar de analizarlos e interpretarlos como indices de cristianismo en el autor. Este proceso, sin embargo, ha sido limitado sólo al estudio de tales elementos en los cuentos. Como se presume que la vida del autor es conocida por los lectores, se mencionarán aquí sólo aquellos datos biográficos que parezcan relevantes para el tema del estudio; porque existen algunos acontecimientos en la vida de Dario que lo pintan en estampa puramente cristiana. Más aún: en el estudio completo de su vida aparece una palpable línea de adhesión a la fe cristiana, que imprime su sello sobre el poeta y lo muestra como cristiano.

Que fue bautizado en la Iglesia. Católica, no cumplidas aún seis semanas de su vida y que recibió los últimos Sacramentos poco antes de su muerte, son hechos fácilmente comprobados y documentados fehacientemente. ${ }^{1}$

Pero entre estos dos polos de su existencia, Darío parece haber recorrido toda la gama de la experiencia humana; de tal manera que, a veces, vivió al margen de las prácticas cristianas. Con todo, no existe una sola prueba de que jamás se haya apartado del pensamiento cristiano. Pero

1 Una copia de su partida de bautismo puede verse en el Archivo Parroquial de León, Nicaragua. 
más eficientes que esta prueba negativa son las pruebas bastante positivas de sus sentimientos cristianos, revelados en los temas, en las alusiones doctrinales y en el vocabulario de sus cuentos. ${ }^{2}$ Estos principios o elementos de cristianismo, pueden observarse en más de la mitad de la colección total de los setenta y nueve cuentos de Darío, editados por Ernesto Mejía Sánchez. ${ }^{2}$

Aun cuando no todas sus composiciones tratan este tema con igual penetración, un estudio detenido revela un significativo enlace de su conocimiento religioso con una profunda aceptación de lo que ese conocimiento encierra. Y, además, en ninguna parte se revela su rechazo o su irreverencia.

Considerando primero los cuentos basados en temas religiosos, encontramos diez y ocho graduados en su intensidad de percepción desde los de mínimo significado hasta los que tocan problemas que encarnan el centro mismo del cristianismo.

El primer grupo nos presenta a Darío familiarizado con las ceremonias religiosas y el culto. En La Virgen de la paloma, Cartas del pais "azul y Un sermón, no sólo nos describe las ceremonias de una bendición y el contenido de un sermón, sino, además, los sentimientos interiores que aquellas sagradas ceremonias iban produciendo en él. En una de éstas, como él lo recuerda, cayó de rodillas: "Y entonces oré, oré, como cuando niño juntaba las manos pequeñuelas". Esta experiencia fue brevemente vivida en toda intensidad, porque saliendo a la calle y respirando el aire frío de la noche, según sus recuerdos: "El asceta había desaparecido de mí; quedaba sólo el pagano" (p. 69). Que sean o no tales escenas ficticias o autobiográficas es de poca importancia. Pero el hecho es que en ellas trata Darío de un tema cristiano en substancia: La lucha entre el espíritu y la carne, entablada en el alma. Y que el autor es consciente de su combate, se halla declarado en su expresión paradojal: "Oré, oré como un creyente en un templo, yo el escéptico!" (p. 68).

En otro grupo de eventos en el que figura La resurrección de la rosa, El nacimiento de la col, y Las pérdidas de Juan Buenro, aparece Darío entrelazando el sentir cristiano con humorísticas leyendas. ${ }^{3} \cdot Y$ es aquí,

2. Rubén Darío, Cuentos Completos (México, F. C. E., 1950), p. 68. Todas las referencias de páginas incluidas en el texto, están tomadas de esta edición.

3 En Las pérdidas de Juan Bueno, Darío describe a San José como un amable, paciente benefactor de Juan Bueno, quien está siendo vergonzosamente engañado por su mujer. En las muchas pérdidas que soporta, busca ayuda en San José; el cual nunca falla en hacerle encontrar las cosas perdidas: hasta que un día viene a buscar ayuda para encontrar a su mujer que se ha perdido. En ese momento, el paciente San José pierde la paciencia, y recomienda a Juan que en esta ocasión lo mejor es emplear la ayuda del demonio! 
en su encantadora sencillez y en su familiaridad con las cosas sagradas, donde el lector recibe la impresión evidente de que el autor fue de verdad un creyente. Un extraño a la fe jamás podría hablar en semejante tono; como tampoco habrian podido sus contemporáneos no cristianos poner tales notas de humor en una literatura de este estilo. ${ }^{4}$

Los tres cuentos siguientes, El árbol del Rey David, La muerte de Salomé e Historia prodigiosa de la princesa, todos derivan de fuentes bíblicas. $Y$ aun cuando estas historias están cargadas de detalles brotados de la imaginación poética del autor, revelan sin embargo el rico tesoro de conocimientos escriturarios que poseía. Se ve, además, que él había bebido profundamente en estas fuentes por la fácil mezcla del latín con el castellano, por ejemplo, cuando habla del apóstol Tomás, dedicado a su misión en la India, donde convierte: "muchas almas para el cielo y para la gloria de Nuestro Señor Jesucristo, Salvador del mundo, al cual sean gloria, honor e imperio, per infinita saecula saeculorum. Amen" (p. 87).

Aunque reconocemos que un tal didactismo no se halla en los escritos de Dario, sin embargo, en los tres cuentos siguientes se manifiesta su preocupación por enseñar las virtudes cristianas a la juveritud. En efecto, en El perro del ciego, La pluma azul y El Dios bueno, son enaltecidas virtudes tales como la mansedumbre, la sencillez, la bondad y la tierna devoción a la Virgen Madre de Dios. Es interesante notar que el último cuento mencionado fue subtitulado por Darío, "Cuento que parece blasfemo pero no lo es". ${ }^{5}$ Que él haya temido que pudiera interpretarse así es algo enigmático. Una posibilidad es que Darío pudo haber temido que se le criticara el permitir que la fervorosa plegaria de un huérfano no fuera respondida. Si tal fue su temor, debemos recordar lo que un eminente autor católico ha dicho concerniente a los escritores que siempre se esfuerzan por dar a sus obras final feliz: Su actitud manifiesta una traición a la enseñanza cristiana, porque el misterio del sufrimiento es hoy, como fue en el Calvario, una parte integrante del Cristianismo. Hacer de la plegaria un remedio mágico para todas las enfermedades del hombre es una negación del mensaje de Cristo. ${ }^{6}$ La actitud, pues, de Darío, lejos de ser blasfema, parece cumplir con lo que es considerado como lo mejor en la novela católica.

4 Blanche Mary Kelly, Well of English (New York, 1936), p. 229.

- El cuento se refiere a un orfanato que no escapa a las bombas en tiempo de guerra. Una de las niñas, despertada por el ruido, se arrodilla en su cama y reza a la Madre de Dios. Pero su plegaria es interrumpida por una bomba que da un golpe mortal a una de las religiosas que se encaminaba hacia la niña arrodillada. .Entonces la niña grita en medio del terror: "iOh buen Dios, no seas malo!" p. 14.

6 Hermana Mariela Gable, Esta es una Novela Católica (New York, 1948), 
En las leyendas que Dario ha entretejido con los temas religiosos encontramos que, mientras muestra su familiaridad con la tradición cristiana comúnmente aceptada, él las adorna con detalles imaginarios y mitológicos. Estos son los chispazos peculiares de su estilo que dan completa originalidad a sus escritos y que no vician ni desfiguran el pensamiento cristiano. Más bien presentan al poeta en sí; y de este modo, no deben confundirse con el deseo de aparecer irreverente o heterodoxo. Por el contrario, él parece confirmar su ortodoxia al referirse a Martín con las palabas "beati Martini confessoris tui atque pontificis" (p. 268), tal como es invocado en el Misal Romano, en la misa de su fiesta, el I I de noviembre.

Otros dos cuentos, Palimpsesto I y $V$ oz de lejos, son menos creyentes de hecho, pero respetuosos en su tono. El primero trata de la sangre que se adhitió a la lanza de Longinos y que llegó a ser un agente eficaz de curación; mientras que la diabólica acción de Judas recibió su justa retribución en su auto-destrucción. Pero a fin de que no aconteciera que la lección de estos dos opuestos efectos de la Cruz de Cristo no apareciera suficientemente realzada, Darío concreta el pensamiento en este párrafo final: "Quién preferiría la cuerda del traidor al arma de la gracia?" (p. I99).

En Voz de lejos, Darío usa como protagonistas personajes inventados; pero el cuento se ha incluido también en este grupo porque el tema se basa en la conversión de aquéllos, de una vida de maldad a otra de plegaria y penitencia.

El sexto y último grupo de cuentos que hemos considerado por razón del tema, lo componen dos que tratan de miembros de órdenes religiosas.

El primero de ellos, Cuento de Nocbe Buena, relata la mística experiencia de un monje ejemplar, llamado Longinos, que ha perdido el camino, a su vuelta al monasterio, en una noche de Navidad. Su oración para ser guiado es respondida por la aparición de una brillante estrella sobre su cabeza. Siguiendo su luz, encuentra a Melchor, Gaspar y Baltasar, que van también guiados por ella. No han llegado aún al pesebre, cuna de Cristo Niño, cuando se da cuenta Longinos de que mientras los tres Reyes son portadores de preciosos presentes, él ha venido con las manos vacías. Cayendo de rodillas, ora así: "Toma, Señor, mis lágrimas y mis oraciones, que es todo lo que puedo of rendarte" (p. 225). Ante el asombro de los tres Reyes, las lágrimas que caen de los ojos del monje se convierten en diamantes de extraordinario esplendor. La escena se traslada entonces al monasterio, donde los monjes están reunidos para Vísperas. A pesar de que Longinos está ausente de su puesto en el órgano, y de que nadie se ha preocupado de llenar aquel sitio, cuando el prior entona el principio del salmo, el órgano acompaña milagrosamente el canto. Poco después de 
este acontecimiento, Longinos entrega su alma a Dios, y muere "en olor de santidad". "Su cuerpo se conserva incorrupto bajo el coro de la Capilla en una tumba especial labrada en mármol" ( $p .225$ ). Darío se nos presenta aquí acercándose mucho al concepto católico del orden místico. Porque si esto se juzga desde un punto de vista puramente literario, el lector se halla frente a defectos de tiempo y ejecución; mientras que si se explica a la luz de una experiencia mística, que trasciende la materia, se ve que está de acuerdo con la enseñanza cristiana.

La muerte extraña de Fray Pedro, el segundo cuento de este sexto grupo que versa sobre la vida monástica, es un penetrante estudio sobre un sacrilegio, en conflicto con los ministros de la Divina Gracia en el alma humana. Fray Pedro es descrito como un monje pálido, enflaquecido y nervioso, que ha sido vencido por el mal. En el monasterio, su tiempo está distribuido entre la oración, el estudio y el laboratorio. Pero fue desgraciadamente el último el que despertó su mayor entusiasmo, de tal manera que un día esto vino a apartarlo poco a poco del cumplimiento de sus otras obligaciones. En una época en que la fotografía y los Rayos $\mathrm{X}$ eran proclamados los últimos descubrimientos científicos, Fray Pedro atribuyó a estos hechos algo casi vecino a la Divinidad. Consumido por la curiosidad ,que creció casi hasta la obsesión, jugueteó con la idea de probar lo espiritual con los mismos medios con que exitosamente había tratado la materia. Fue así, pues, como trató de analizar el Misterio de la Eucatistía sometiendo a los Rayos $\mathrm{X}$ una hostia consagrada. La culminación de su experimento es revelada cuando se descubre su cuerpo exánime, en el umbral de su celda, tendido junto a una fotografía en la que aparecía "con los brazos desclavados y una dulce mirada en los divinos ojos, la imagen de Nuestro Señor Jesucristo" (p. 329).

El mismo Darío no dio la clave de este simbolismo, obscurecido bajo las formas de su palabra; pero la sinceridad con que narra la historia y la evidente conciencia que tiene de que el hecho que está describiendo es un sacrilegio, parece indicar la realidad de que su preocupación no fue una mera expresión literaria.

A la luz de estas observaciones, resulta difícil comprender porqué Darío haya sido considerado como superficial y preocupado con la pintura y musicalidad de las palabras más que con su papel de ser. las portadoras del pensamiento humano. Posiblemente se encuentre una explicación de esta interpretación errada en su dictum estético mismo de que un pocta no es responsable de hacer su obra inteligible a sus lectores. Más bien él escribió para un selecto grupo, cuya aceptación él sabía asegurada (P. Io).

Pasando ahora de estos cuentos, basados en temas religiosos, a aquellos 
que tienen en sus páginas sólo algunas alusiones a verdades de la Fe Católica, notamos también en éstos una aceptación y un reconocimiento de lo que esas verdades encierran. Y no obstante el hecho de que Darío, de esta manera, no comprometía su ideal poético de "El Arte por el Arte", empleándolo como un medio de enseñanza religiosa, la realidad del Dogma Cristiano no es menos evidente en sus cuentos.

Desde los misterios básicos de la Vida (pp. 156, 224, 285), Muerte (pp. 199, 224), y Resurrección de Cristo (pp. 285, 309), Darío se encamina a los de la Unidad (p. 3I2) y la Trinidad (p. 312 en Dios, expresando así un sencillo pero comprensivo conocimiento de los dogmas en que está basada la Iglesia Católica. Alusiones sobre cada uno de estos misterios aparecen no sólo una vez, sino frecuentemente en el curso de sus cuentos.

Pero además de estos misterios básicos y profundos, como innegablemente lo son, existen otros que parecen indicar una más intima penetración en la vida cristiana y que Darío también los incluyó en su obra.

En El Dios Bueno, con bastante reverencia y admirablemente, trata de la Presencia Real cuando al través de las palabras del niño huérfano expresa: "La hostia es santa, blanca y redonda... cuando el padre alza la custodia tres veces sobre su frente me está mirando el buen Dios que me ama" (p. 136). Y en singular contraste con este niño, cuya fe fue momentáneamente suspendida [éxtasis] para que pudiera reemplazarla la misma realidad, está el fraile cuya historia se relata en La muerte extraña de Fray Pedro. Porque aquí el desgraciado religioso, víctima de "el pecado bíblico de la curiosidad" (p. 328), comercia su fe en Dios por su creencia en la ciencia y profana el "Santísimo Sacramento". Pero si las manos de Fray Pedro son irreverentes al tocar aquella Sagrada Forma, no hay con todo irreverencia en las palabras que describen el desgraciado incidente, ni puede haber duda en nosotros de que el autor sabía que el hecho que describía era un sacrilegio.

Referencias sobre la enseñanza cristiana acerca de la maternidad de María para con todos los hombres, se encuentran también en El Dios Bueno. La creencia del poeta en la paternidad de Dios y en su cuidado providencial por sus hijos, se expresa en $E l$ año que viene siempre es azul y Mi Tía Rosa.

Aunque el temor de Darío por la muerte - temor que llegó a las alturas de la fobia, como la mayor parte de sus biógrafos lo han observado- fue real, con todo, no fue el temor pagano de cierta vaga aniquilación de su ser. Tuvo, por el contrario, una vívida comprensión de la inmortalidad del alma humana, como lo expresa en Sor Filomena, cuando habla 
de "las inmortales almas de las bienaventuradas" (p. 237), y del "angelito que voló al cielo" (p. 34I) en La pluma azul.

Posiblemente una señal mayor aún de sus convicciones a este respecto es su creciente preocupación por las cosas del espíritu, que caracterizó toda su vida y especialmente al comprender que su carrera tocaba ya a su fin. Ansioso como se había siempre mostrado de participar en cualquier placer de la vida que pudiera presentársele, su muerte se caracterizó por una calma que puso en evidencia su creencia en una vida que trascendía las realidades de la carne.

Además, su conformidad con la doctrina del libre albedrío es evidenciada por la distinción que él describe entre la desnudez del mártir Sebas. tián y aquella de la lasciva Salomé; porque esta distinción es real sólo a la luz del ejercicio de la libre voluntad y personal responsabilidad de los actos morales del hombre.

Son éstas, pues, las ideas que Dario ha expresado con tan persistente conformidad con la creencia cristiana que resulta indudable concluir que fue un cristiano en toda la extensión de la palabra. $Y$ precisamente porque ha sido por medio de sus cuentos cómo muchas de estas ideas han sido reveladas, parece lógico, como consecuencia, colocar los cuentos dentro de la esfera de la tradición cristiana.

Existe además, aunque más remoto, otro indicio de cristianismo, tanto en el conocimiento como en los sentimientos del poeta, que se descubre en sus cuentos. Allí donde Darío trata extensamente de temas y dogmas cristianos necesariamente emplea el correspondiente vocabulario cristiano; pero aun en los cuentos que contienen materias no propiamente cristianas su sentimiento religioso aparece evidente. ¿Qué causa, en verdad, sino su propia convicción interior habría podido moverlo suficientemente a emplear un lenguaje esculpido en cristianismo, para expresar ideas que no eran cristianas? Y en Darío acontece esta fusión con una frecuencia y facilidad tal que difícilmente podría realizarse si fuera solamente un adorno lingüistico.

Por ejemplo, en Bouquet, describe el lirio como: "Flor santa y antigua. La Biblia está sembrada de azucenas. El Cantar de los Cantares tiene su aroma halagador" (p. 27). Ciertamente no fue sólo la mera fácil familiaridad con la Biblia, lo que despertó esta comparación en la mente del autor.

En La canción del oro, severa en su condenación del rico por su insensibilidad para con el pobre, Darío ha acudido a una cita bíblica para su descripción del "oro purificado por el fuego como el hombre por el sufrimiento" (p. 73). Habla además aquí de la despreocupación por las rique: 
zas, mostrada por los ermitaños Pablo, Antonio e Hilarión. En La novela uno de los tantos hay también una alusión a San Martín en esta declaración: "yo soy como el Santo de la capa que le dio la mitad al pobre" (p. 147).

Ni está tampoco su conocimiento limitado de alguna manera por el tiempo o por las materias; antes bien manifiesta una extensa familiaridad con las fuentes más importantes del pensamiento cristiano. Hay, por ejemplo, una alusión al Cantar de los Cantares del Antiguo Testamento como también a una Epístola de San Pablo en el Nuevo Testamento. Hay además un pasaje de Santa Teresa, y un eco de la súplica de Cristo desde la Cruz. Más remotamente, en los cuentos ya citados por razón de sus elementos cristianos, encontramos también palabras y expresiones de particular significación. Hay, verbi gratia, alusiones a los Vasos Sagrados o expresiones litúrgicas, que indican reverencia por aquello que merece ser tratado con respeto. De aquí que encontremos "la custodia cubierta de pedrería", "el copón", "el órgano acompañando la antífona" y "maitines o vísperas" (p. 48). Se incluyen también palabras que reflejan la familiaridad de Darío con los términos habituales en la rutina de la vida religiosa, tal como "diácono" (p. 268), "las disciplinas", "Ias horas litúrgicas" y "la Sagrada Forma" (p. 328). En otra parte él ha incorporado a su texto pasajes completos de la Escritura o del Misal Romano. Y a fin de realzar la piedad cristiana del neófito Martín, hace referencia a los ídolos de la Grecia Clásica: "nada para él de Dionisio; nada de Venus. $\mathrm{Y}$ en aquella carne de firme bronce está incrustada la margarita de su castidad" (p. 265). Describe aquí también la visión de Martín acerca de Dios: "viene el Pobre, viene N. S. J. C." (p. 266).

Existen otros ejemplos; pero estos son suficientes para expresar el íntimo conocimiento de la Liturgia y la Escritura que Dario unió a una familiaridad de trato que de ninguna manera aminoró la reverencia que el tema requería.

Tal es el tono del vocabulario que Rubén Darío utilizó a través de estas obras en prosa. Y aunque debe aceptarse que existe también en sus obras una abundante dicción de estirpe claramente pagana, este hecho no destruye lo que hasta aquí se ha demostrado. Tampoco ha sido nuestro intento el clasificar a Darío como un autor religioso. Más bien ha sido nuestro deseo el traer a la luz la corriente de conocimiento religioso que fluye al través de sus escritos; pero esto nos ha sido posible sólo al sumergirnos debajo de lo que es pagano y no religioso.

Que la mera presencia de expresiones religiosas o símbolos cristianos no constituye por sí solo una literatura religiosa, es algo claramente cono- 
cido. Pero la prodigalidad con que Dario ha empleado la terminología de la Escritura atestigua tanto su familiaridad como su respeto por lo que se contiene en el Antiguo y el Nuevo Testamento. Su frecuente alusión a la Liturgia manifiesta su veneracón por su forma y su admiración por su belleza. Y, más que nada, el hecho de que todo cuanto Darío escribió fue fruto de una constante selección, vigoriza la creencia de que su vocabulario debe ser considerado como un signo de su convicción interior. Finalmente, la reverencia que manifiesta por la creación de todo hombre, también descubre un espíritu totalmente conforme con la enseñanza cristiana.

Para aquéllos que todavía deseen señalar su uso de formas y símbolos paganos, que por cierto existen en estas páginas, los remitimos, al ejemplo de muchísimos autores cristianos, y aun a Doctores de la Iglesia. ¿Acaso no ha basado Tomás de Aquino su Sistema Escolástico en el método ya formulado por Aristóteles? ¿Y es Agustín menos cristiano por sus citas de Platón?

Que pudieran existir, evidentemente, influencias cristianas y paganas en sus obras es, por otra parte, el resultado natural de la dualidad de su naturaleza, donde se entabló la lucha entre estas dos fuerzas, desde una edad asombrosamente tierna casi hasta el último suspiro; pero la persistencia de esta lucha claramente atestigua el hecho de que, mientras ni la una ni la otra fue capaz de vencer, Darío jamás abandonó el combate. Y hacia el término de su vida, su creciente preocupación por el espíritu y su final sumisión a la Gracia, no nos dejan duda ni de la sinceridad de sus esfuerzos ni de la legitimidad de su sentimiento.

Si existe, pues, $\tan$ considerable acopio de pruebas acerca del conocimiento cristiano como del reconocimiento de la enseñanza cristiana, ¿cómo explicar, entonces, el enigma de las frecuentes alusiones al paganismo de Dario? Como, por ejemplo, la de Enrique Anderson Imbert, quien hablando del hedonístico tono del trabajo de Darío sugiere que esto proviene de un acto deliberado de la mente, por el cual él establece el placer como finalidad de la vida." Y Marquina lo llama "el pagano que ha vivido en Roma y Grecia, venido del Extremo Oriente... que vivió toda su vida secuestrado en el culto de la dignidad de su arte". ${ }^{8}$ Esta aparente contradicción queda probablemente muy bien explicada a la luz de dos consideraciones. Primero, Rubén Darío fue un esteta, y en su búsqueda del culto de la belleza, no reconoció límites de cultura ni credo. Este discernimiento

7 Enrique Anderson Imbert, Historia de la literatura bispanoamericana (México, 1954), p. 215.

8 Oscar Beltrán, Manual de bistoria de la literatura bispanoamericana (Buenos Aires, 1938), p. 244. 
estético lo capacitó para percibir lo bello en los sitios más recónditos. Esta oscuridad en nada aminoró sino que más bien enalteció su atractivo para él. Así encontramos su obra empapada en los tesoros escogidos de las culturas asiática, oriental, helénica y renacentista, del mismo modo como la encontramos hermoseada por la Sagrada Liturgia y el ornato medioeval. Fue sólo así, mediante este vasto acervo, como pudo expresar plenamente el genio que en él se guardaba.

En segundo lugar, él fue un poeta, aun en su prosa; y un poeta no puede limitar su lirismo a lo que es sólo forma, materia o idealismo cristiano. Instintivamente fue enemigo de toda limitación que pudiera sofocar o hacer estéril esta libertad de expresión. Por tanto, esta amplitud poética, más bien que un voluntario rechazo de principios cristianos, fue quien lo condujo a incluir profusamente en su obra elementos no cristianos.

Finalmente, la cultura en que él se formó, parte había sido infiltrada de la tradición clásica, en la que formas y símbolos paganos eran medios reconocidos en la expresión del arte. $Y$ en esto, estuvo en completo acuerdo con el eclecticismo latinoamericano, que estaba libremente informado por la herencia greco-romana. De esete modo, cuando Dario comparó a Nuestra Señora con Venus, tomó la imagen que, según la mente clásica, era la personificación e idealización de la belleza; y por lo tanto, la única comparación digna de "la Mujer vestida del Sol" de San Juan. ${ }^{9}$ No de otro modo debe entenderse su descripción del cielo lleno de deleites perfumados y saboreos de carne femenina, según el voluptuoso sentir del poeta clásico; pero despojados de su imaginación y de su música, los conceptos fundamentales son teológicamente cristianos.

Otra idea, aunque más lejana, pertinente a la comprensión de su sentimiento, es que esta mezcla de elementos cristianos y no cristianos en las obras de Darío, jamás se encaminó al libertinaje o a la vulgaridad. Una innata delicadeza lo mantuvo al margen de estas cosas. $Y$ debido a esta delicadeza, su obra ha podido remontarse a las alturas de la belleza, y con. vertirse en digno vehículo de los sentimientos cristianos que se sienten flotar al través de lo mucho que escribió.

El que haya sido capaz de preservar la integridad de su sentir cristiano, a pesar de las contrarias influencias que se palpan en sus obras, es efecto de una intrínseca tendencia a identificar la verdad con la belleza; de tal manera que para él, el Arte Puro y Cristo, son un solo todo, como brillantemente lo expresa en uno de sus poemas:

- Apocalipsis, 12:1. 
Vida, luz y verdad, tal triple llama

Produce la interior llama infinita;

el Arte puro como Cristo exclama:

Ego sum lux et veritas et vita!10

Hermana Mary Avila, C.S.J.

St. John's University, N. Y. p. 50 .

10 Rubén Dario, "Spes", Cantos de Vida y Esperanza (Barcelona, 1905), 
